\title{
IMPLEMENTASI DYNAMIC PROGRAMMING PADA PENENTUAN JENIS MATERIAL UTAMA BANGUNAN ARENA \\ FUTSAL
}

Andree Anthony ${ }^{1}$
dreanth@gmail.com
R. Gunawan Santosa ${ }^{2}$

gunawan@ukdw.ac.id

\author{
Yuan Lukito ${ }^{3}$ \\ yuanlukito@ti.ukdw.ac.id
}

\begin{abstract}
:
Building Futsal court need some planning, especially about the materials needed to build a Futsal court such as synthetic grass, roofs, walls, benches and some other materials. Each of materials have many choices usually based on quality and price. Thus it needs a system to assist on calculating the optimum materials combination based on a specified budget. Minimax Route method are used with dynamic programming techniques to maximize the quality of materials while minimizing the price of materials chosen. Based on system testing conducted to Futsal court owners in Yogyakarta, the implementations are helpful and have many useful information for someone who want to build a Futsal court.
\end{abstract}

Keywords: dynamic programming, minimax route, Futsal court

\section{Pendahuluan}

Membangun suatu arena futsal jelas membutuhkan persiapan yang matang. Budget dan pemilihan material tentu merupakan hal yang sangat penting. Pemilihan barang dengan kualitas dan harga dari kebutuhan pembangunan merupakan pertimbangan utama saat akan membangun arena futsal. Kesalahan dalam memilih kebutuhan material pembangunan arena futsal akan menjadi penyebab utama membengkaknya biaya yang harus dikeluarkan.

Oleh sebab itu dibutuhkan sebuah program bantu yang dapat menemukan kombinasi pilihan barang material yang tepat untuk pembangunan arena futsal. Program itu sendiri dapat dilakukan dengan memperhitungakan nilai harga dan kualitas dari setiap barang material yang dibutuhkan untuk membangun arena futsal. Karena tidak setiap orang bias memperhitungkannya maka dibuatlah sebuah aplikasi bantu dengan menggunakan metode Dynamic Programming Minimaks Route sehingga sistem dapat memberikan kebutuhan material yang sesuai dengan biaya yang dimiliki dengan tetap menggunakan prinsip meminimalkan biaya dan memaksimalkan kualitas yang ada.

\section{Landasan Teori}

\subsection{Dynamic Programming}

Dynamic Programming menentukan solusi optimal dari masalah multivariabel dengan menguraikan permasalahan ke dalam setiap tahap (stages), setiap tahap terdiri dari subproblem variabel tunggal yang kemudian subproblem tersebut digabungkan kembali. Keuntungan dari pemecahan masalah ini adalah proses optimasi pada setiap tahap melibatkan satu variabel saja (Taha, 2007).

\footnotetext{
Program Studi Teknik Informatika, Fakultas Teknologi Informasi, Universitas Kristen Duta Wacana.

2 Program Studi Teknik Informatika, Fakultas Teknologi Informasi, Universitas Kristen Duta Wacana.

${ }^{3}$ Program Studi Teknik Informatika, Fakultas Teknologi Informasi, Universitas Kristen Duta Wacana.
} 
Ciri-ciri dari dynamic programming antara lain :

1. Keputusan suatu masalah ditandai optimisasi pada tahap berikutnya.

2. Masalah yang akan diselesaikan harus dipisah menjadi n subproblem.

3. Dynamic Programming berhubungan dengan masalah-masalah dimana pilihan dibuat pada masing-masing tahap (stage). Seluruh kemungkinan dicerminkan oleh keadaan (state).

4. Setiap keputusan pada tahap-tahap mempunyai fungsi return yang akan mengevaluasi pilihan yang dibuat terhadap tujuan keseluruhannya ( $\mathrm{max} / \mathrm{min}$ ).

5. Tahap proses keputusan dihubungkan dengan tahap yang berdekatan melalui fungsi transisi.

6. Ada hubungan rekursif yang menghubungkan optimasi terhadap $n$ dengan tahap ( $\mathrm{n}$ 1) atau menghubungkan optimasi tahap $\mathbf{n}$ dengan tahap $(\mathrm{n}+1)$. (Winston,2001)

\subsection{Kriteria Minimaks}

Menurut Taha (2007), kriteria minimaks didasarkan pada sikap konservatif dalam membuat yang terbaik dari kondisi yang paling buruk. Jika v $\left(a_{i}, s_{j}\right)$ adalah kerugian, maka kita memilih tindakan yang berhubungan dengan kriteria minimaks

$$
\min _{\mathbf{a}_{i}}\left\{\max _{\phi_{j}} v\left(a_{i}, \phi_{j}\right)\right\}
$$

\section{Hasil dan Pembahasan}

\subsection{Alur Sistem}

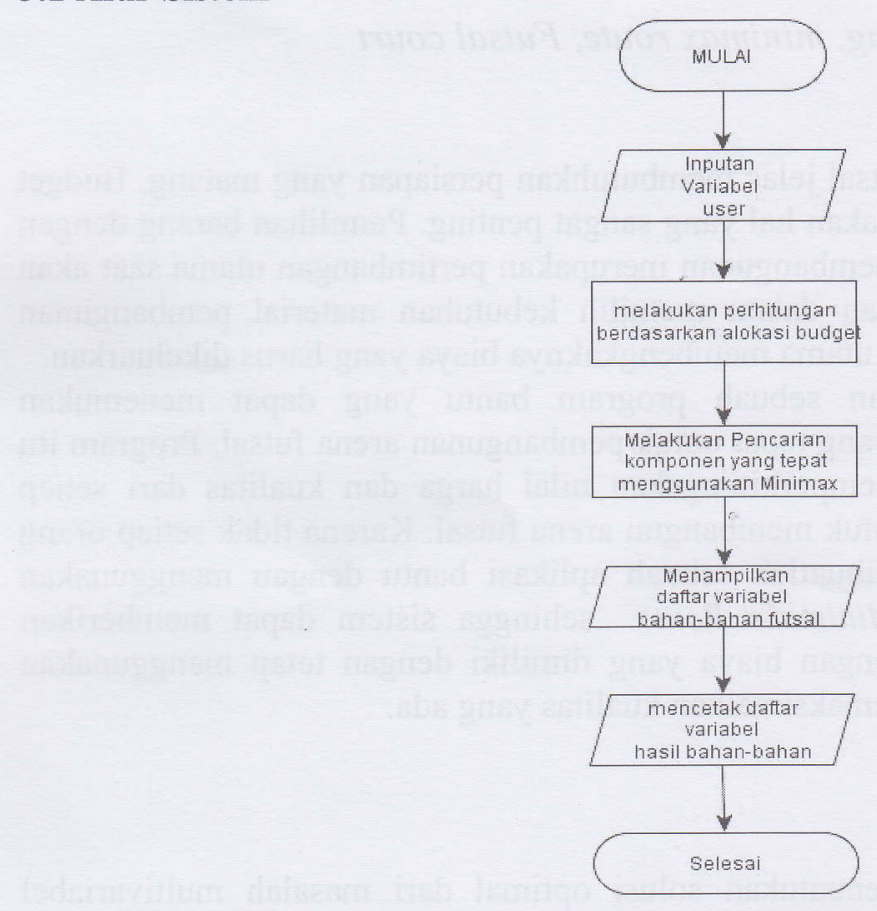

Gambar 1. Alur Sistem

Pada gambar 1 merupakan diagram alir dari sistem, secara keseluruhan, dimulai dari pengguna melakukan input biaya yang dipunya, sistem yang langsung melakukan perhitungan sesuai dengan alokasi biaya yang dipunya, kemudian sistem mencari variabel yang sesuai dengan biaya yang dimiliki oleh pengguna dengan menggunakan algoritma minimaks, selesai melakukan proses perhitungan sistem menampilkan hasil yang didapat dari variabel yang sesuai dengan biaya yang dimiliki oleh pengguna, sistem kemudian mencetak hasil yang sesuai dengan biaya, kepada pengguna. 


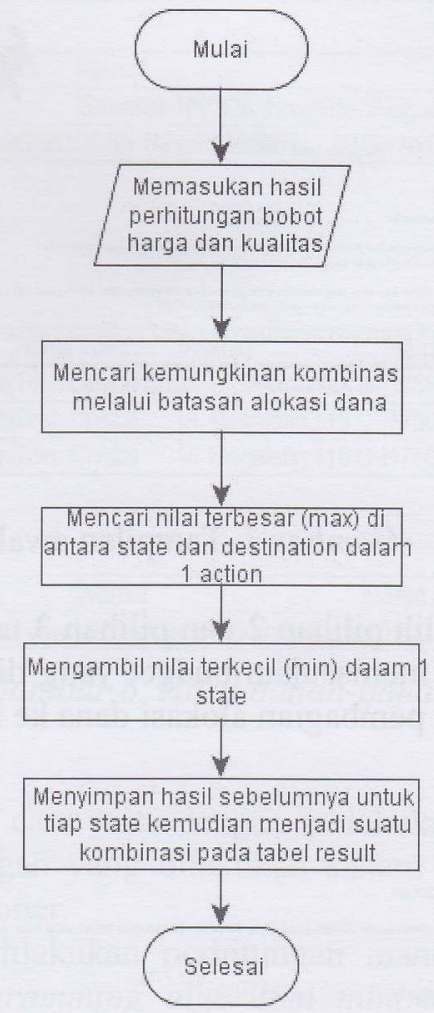

Gambar 2 Diagram alir minimaks route

Pada gambar 2 merupakan proses algoritma minimaks yaitu proses pencarian kemungkinan kombinasi yang didapat sesuai dengan batasan dana yang ada, mencari nilai max dari 1 action yang ada, dari hasil nilai max yang ada pada variabel tersebut kemudian dicari nilai min pada 1 state yang ada, kemudian disimpan hasil dari 1 variabel yang ada kemudian dilakukan hal tersebut lagi untuk mendapatkan variabel yang lain sehingga didapat kombinasi variabel yang ada untuk pengguna.

\subsection{Implementasi Sistem}

Pada gambar 3 berikut ini merupakan tampilan awal dari sistem, merupakan implementasi halaman awal(index). Pada halaman ini pengguna dapat memilih 3 pilihan yang ada. Pilihan 1 ditujukan kepada pengguna yang benar-benar tidak mengerti bahanbahan yang diperlukan untuk membangun arena futsal dan memiliki dana tinggi, maka sistem akan memberikan rekomendasi hasil bahan-bahan yang akan digunakan, dengan kualitas yang bagus dan harga yang mahal. Pilihan 2 ditujuakan kepada pengguna yang mempunyai dana yang terbatas tetapi tidak mengetahui bahan apa yang digunakan maka dapat memilih pilihan 2. Pilihan 3 disini ditujukan kepada pengguna yang memiliki dana terbatas, dan mungkin sudah mengetahui bahan-bahan yang digunakan dan tidak memerlukan seluruh bahan untuk dilakukan perhitungan maka dapat memilih pilihan 3 . 


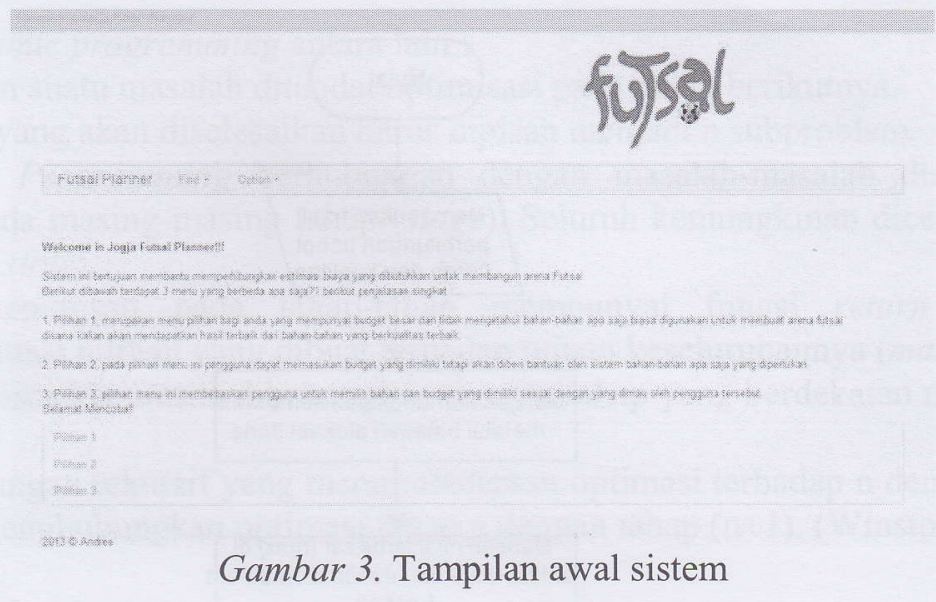

Apabila pengguna memilih pilihan 2 dan pilihan 3 maka akan muncul lanjut ke proses berikutnya setelah pengguna memasukan budget yang dipunya, pada halaman selanjutnya dari proses merupakan proses pembagian alokasi dana ke setiap bahan/variabel, seperti pada gambar berikut :

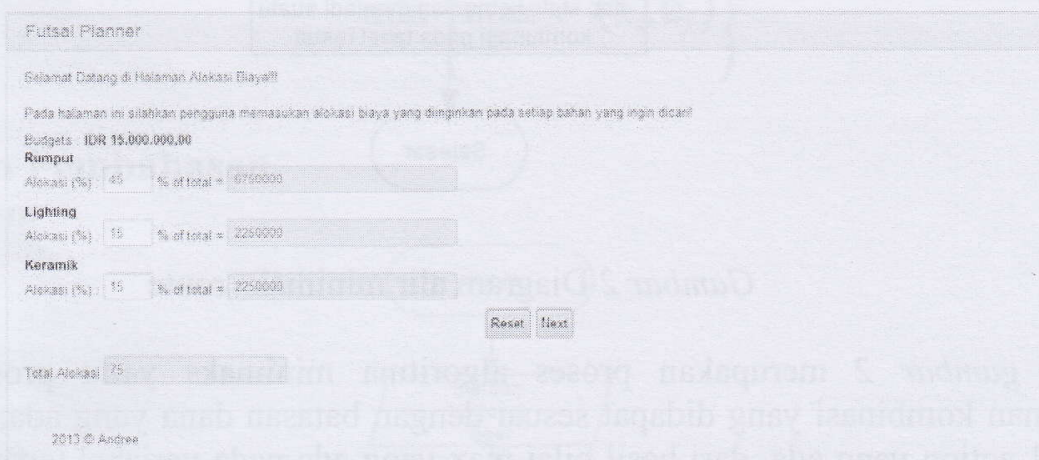

Gambar 4. Halaman pembagian alokasi

Setelah melakukan pembagian ke setiap bahan yang ada, pengguna dapat memilih menu next untuk menuju halaman pembobotan kualitas dimana pada halaman tersebut pengguna memasukan berapa prosentase kualitas yang diinginkan oleh pengguna untuk setiap bahan yang terpilih, setiap bahan mempunyai presentase $0-100 \%$ seperti pada gambar 5 berikut,

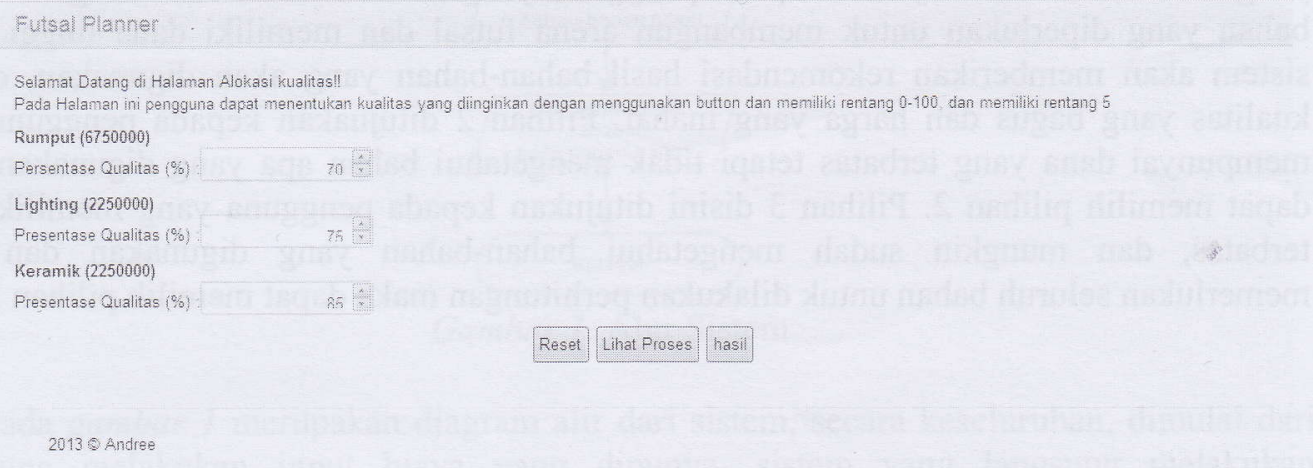

\section{Gambar 5. Presentase Kualitas}

Pada halaman presentase kualitas terdapat 3 tombol yaitu reset untuk mengatur ulang presentase kualitas yang ada, kemudian tombol Lihat Proses merupakan untuk melihat proses penghitungan, button hasil akan memunculkan hasil bahan-bahan yang sesuai dengan dana yang dimiliki pengguna seperti pada gambar 6 berikut 
Rumput:

\begin{tabular}{|c|c|c|c|}
\hline Nama Barang & Nama Toko & Alamat & Harga $/ m 2$ \\
\hline \multicolumn{2}{|c|}{ Rumput Fibrilated Satria } & \multicolumn{2}{|c|}{ Sawahan Rt03/28 Nogotito. Gamping - Yogyakarta 105000} \\
\hline Rumput Fibrilate & EmbassyGra & JI Kh. Hasyim Ashari No. 99 Banten & 105000 \\
\hline
\end{tabular}

Lighting:

\begin{tabular}{|l|l|l|l|}
\hline Nama Barang & Nama Toko & Alamat & Harga m2 \\
\hline Lampu Keong merk Osram Toko Lampu Ero Jl. C Simanjuntak 44 & 175000 \\
\hline Lampu Keong merk Osram Toko Crystal & JI. Magelang 115 C & 175000 \\
\hline Lampu Keong merk Osram Toko Crystal & JI. Magelang 115 C & 175000 \\
\hline
\end{tabular}

Keramik:

\begin{tabular}{|c|c|c|}
\hline Nama Barang Nama Toko & Alamat & Harga $/ \mathrm{m} 2$ \\
\hline Warna Puth Toko Ponda & Jl. Mage & 43500 \\
\hline
\end{tabular}

Gambar 6. Hasil bahan-bahan

\subsection{Hasil Evaluasi}

Evaluasi dilakukan dengan 3 cara yaitu dengan melakukan perhitungan manual untuk membuktikan apakah penghitunagan yang dilakukan sistem sudah cocok, melakukan uji performance dan melakukan kuisioner.

Perhitungan manual disini dilakukan perhitungan manual untuk dapat mengetahui apakah penerapan dynamic programming algorithm minimaks route sudah cocok dan mempunyai hasil sama dengan hasil yang didapat dari perhitungan sistem.

Pada pengujian performance dari sistem didapat bahwa pada waktu uji hasil proses paling mendekati dengan $(\mathrm{O}) \mathrm{n}$ seperti pada gambar 7 berikut

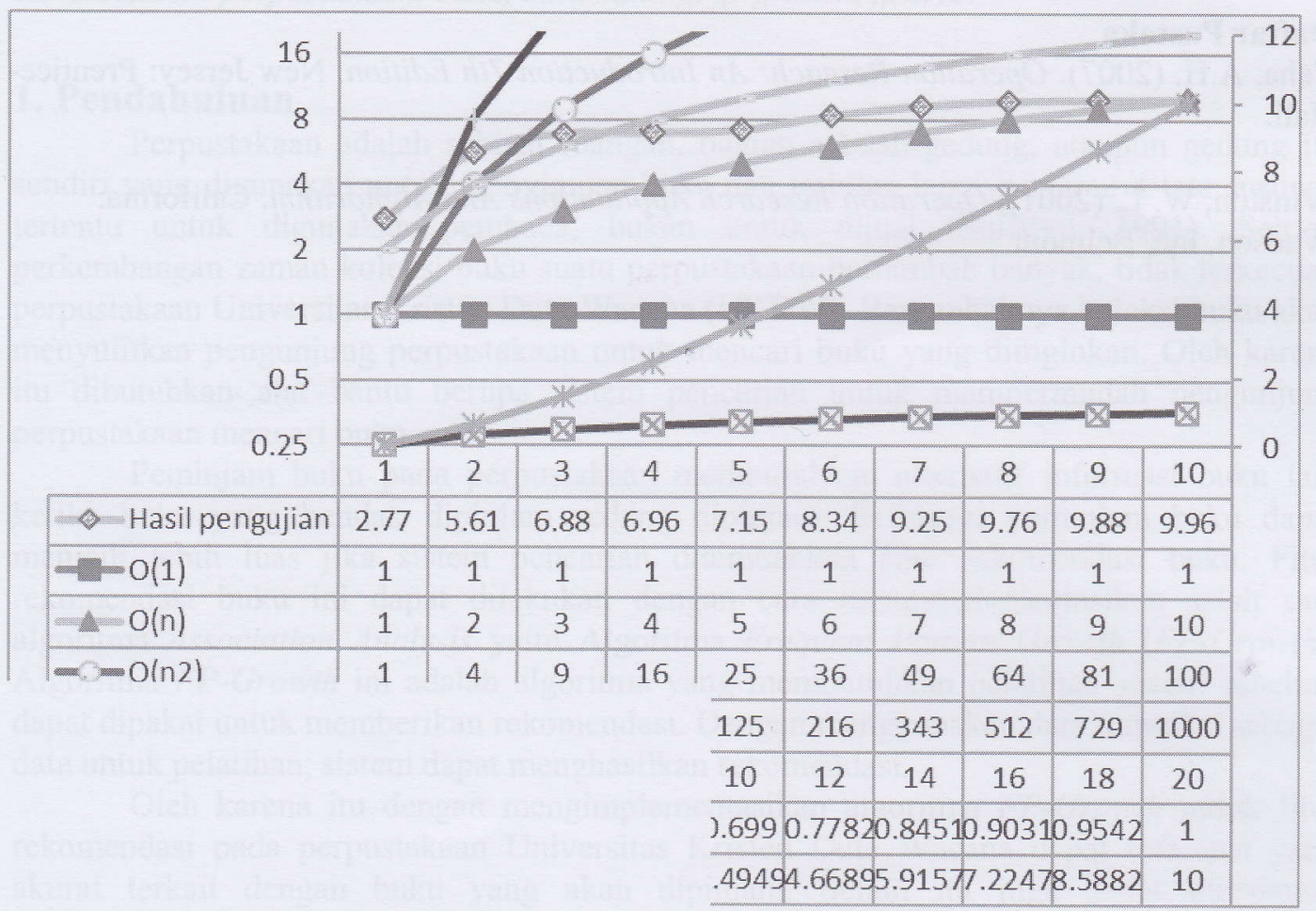

Gambar 7. Uji Performance

Berdasarkan hasil kuisioner didapat bahwa 50\% responden secara keseluruhan setuju bahwa sistem sudah membantu dalam membangun arena futsal, $90 \%$ responden juga tidak mengalami kesulitan dalam mengoperasikan sistem. $50 \%$ responden juga menjawab bahan- 
bahan yang ada sudah cukup lengkap. Meskipun demikian hanya 46\% responden yang menjawab setuju ketika ditanya apakah sistem kelak mampu digunakan dalam membangun arena futsal dan $40 \%$ responden yang menjawab hasil yang dihasilkan sistem sudah sesuai dengan yang mereka inginkan.

Berdasarkan hasil kuisioner didapat sebanyak 29 responden menjawab pengoperasiannya mudah, informasi dan fitur yang ada lengkap dan menarik. Berdasar kuisioner juga dapat disimpulkan responden mengharapkan sistem nantinya dapat memperkirakan jumlah barang yang dibutuhkan, perhitungan biaya-biaya lain juga dapat diperkirana (contoh : biaya tukang, biaya pengiriman barang), dan perlu ditambahkan bahan-bahan yang lain supaya lebih lengkap.

\section{Kesimpulan} berikut:

Berdasarkan analisis dan implementasi sistem, maka diperoleh kesimpulan sebagai

- Penerapan Dynamic Programming Algorithm sudah dapat diterapkan untuk membantu pengguna dalam pemilihan bahan bangunan yang dapat digunakan untuk membangun arena futsal.

- Pengimplementasian Dynamic Programming Algorithm pada sistem bantu yang ada sudah sesuai, dapat dilihat pada pilihan 3 pada program dimana custom pilihan sudah berjalan.

- Sistem mampu memberikan kombinasi bahan kepada pengguna secara efektif dimana terlihat pada kombinasi bahan yang ada sesuai dengan prinsip mendapatkan bahan dengan kualitas sebaik mungkin tetapi tetap memperhitungkan harga sekecil mungkin.

- Dari hasil analisis uji performa didapatkan waktu proses hasil pengujian paling mendekati dengan pengujian $\mathrm{O}(\mathrm{n})$.

\section{Daftar Pustaka}

Taha, A.H. (2007). Operation Reseach: An Introduction 7th Edition. New Jersey: PrenticeHall.

Winston, W. L. (2001). Operation Research Applications And Alghorithm. California: Wadson, Inc. Belmont 